\section{Explanatory tyranny}

\section{If an explanation seems wonderfully simple, it's probably too good to be true.}

\section{Timothy Taylor}

A $s$ an archaeologist, I was not surprised that the human genome comprised far fewer genes than predicted. It had been assumed by some that genes for simple things, such as hair colour, would soon be joined by genes for other things, such as (infamously) homosexuality, also construed as 'simple' by those with inadequate knowledge of the natural history of sexual culture. Belief in a complex causal nexus, not just between genes but between genotype and environment — including the cultural environment, whose profound modifiers are known to extend even to aspects of the intrauterine environment - seemed somehow less scientific than a search for discrete, function-specific units. Perhaps I have no business commenting on genetics, but what I am really interested in is an explanatory imperialism which threatens to subsume even archaeology. The unmet expectation in the genome case signals a wider epistemological malaise affecting public perceptions of what science is and how it should look.

Twenty-five years ago, Richard Dawkins, in The Selfish Gene (Oxford Univ. Press, 1976), proposed the existence of cultural replicators or 'memes' that worked in a similar way to genes. According to this idea, material things (such as mugs), aesthetic objects (such as Beethoven's Ninth Symphony) and ideas (such as God) were copiable codes; "the computers in which memes live are human brains". Dawkins considers his unit good, as it subsequently successfully replicated itself as a word. Indeed, in respect of brief snatches of music or simple and peculiarly uniform artefacts, such as coins, the idea seems to have some applicability.

But in aesthetic philosophy, musical performances are considered tokens of types: each performance of Beethoven's Ninth Symphony is unique and can never be reproduced. And in archaeology, artefacts are not generally considered to constitute species, successful or otherwise. Unlike genes, they

\section{$W_{\text {secoure }}^{\text {nats as }}$}

knowledge is complex, multi-stranded and indefinite. cannot be classified so that any particular 'defining' attribute is both sufficient and necessary for group membership (monothetic classification). In modern Britain the name 'mug' is given to a variety of forms, and no single attribute is both sufficient and necessary for group inclusion (polythetic classification). Whether a mug is able to hold boiling liquid (or not: a beer mug), or made of pottery (or not: a tin mug), or whether a thing with a handle is a mug (rather than a cup or a door), fuzzily constrains how any one object in our culture gets its designation and defined function, connotations, and symbolism. Moving beyond this familiar kind of complexity, anthropologists must attempt to tackle alien classifications, while archaeologists face a further level of difficulty in confronting alien and extinct cultural phenomena. Prehistoric archaeology attempts to observe and explain these without the aid of texts and is therefore - for all its 'the spade never lies' appeal - an exacting philosophical challenge (spades never speak either).

Mugs cannot replicate themselves and memes have not been embraced by cultural theorists. So my protest would be unnecessary were it not for the baleful influence of 'gene-meme' thinking in the recent spate of para-archaeological fantasies which purport to reduce the very great complexities of the human past to a simple formula. Theories that attribute pyramids in both Egypt and Mesoamerica to a uniquely gifted race of mystic astronomers - whether priests of Ra, ancient Antarcticans, or aliens - migrating across continents bringing true culture, have been curiously dignified by the meme idea. Likewise, claims for a standard, memic, unit of measurement, the 'megalithic yard', in neolithic Orkney and Egypt — the secret intellectual property of an international masonic guild — find converts by fulfilling the public's formal expectations of science.

Many architectural structures are broader at the bottom than at the top rather than vice versa, and for good reason. Call them pyramids, but the Giza mausoleums, originally smooth and unclimbable, differ fundamentally from the Mayan temples of 3,000 years later, where ceremonial staircases led to elevated sacrificial platforms. Messy but powerful bayesian methods reveal the chimaera of the 'megalithic yard' too. Layout measurements were based on the human body - hands, feet, paces — which can explain the metrological convergence and coincidence across place and time.

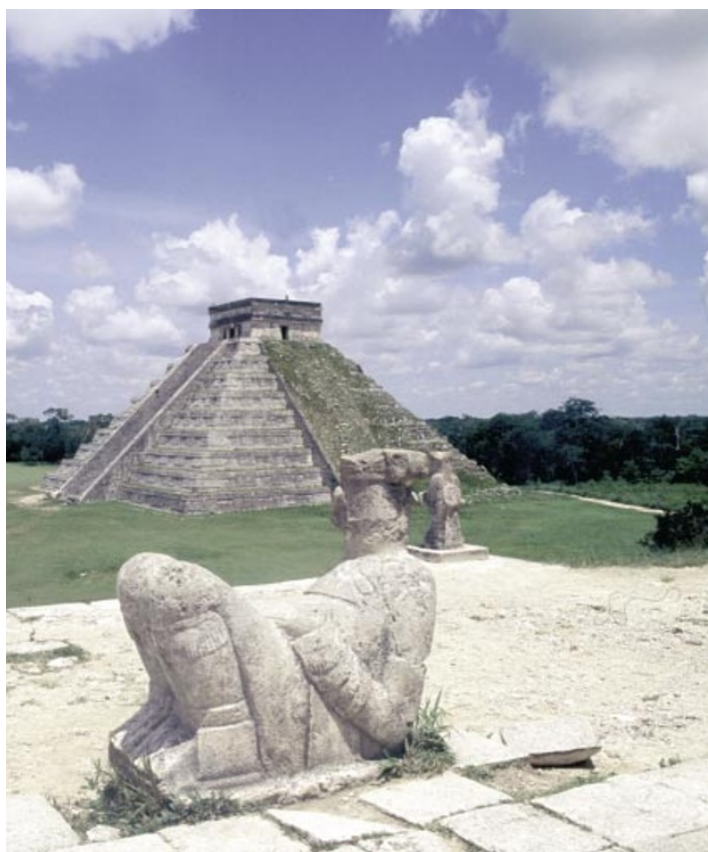

All pyramids? The Mayan temple above differs fundamentally from those at Giza.

Ever since Plato there has been the idea that good explanations should condense into simple formulae. Umberto Eco, in Foucault's Pendulum (Secker \& Warburg, 1989), says "The truth must be simple and sayable: $E=m c^{2}$, knowing full well that things are seldom like that in culture. Oscar Wilde is not just witty, but humane, to observe that "the truth is rarely pure, and never simple". The proper explanation of archaeological phenomena cannot look like $E=m c^{2}$. Archaeology has to explain its subject in terms of 'how ... possibly [did that event occur in the past]' (h-p explanation) rather than 'why ... necessarily [does that always happen in the lab]' (w-n explanation). This reliance on $h-p$ explanation is shared with other systematic endeavours to explain ontologically unique, unrepeatable phenomena, such as the conditions for the creation of the observable Universe or the extinction of the dinosaurs (whether or not these appeal to certain covering laws).

The current ascendancy of the $\mathrm{w}-\mathrm{n}$ form is a response to the perception that the public and politicians need clear leads on how research is conducted. But it is also supported within science, by individuals and committees. Yet all scientific enquiry possesses some historical, ontologically unique dimension, and what counts as secure knowledge in the explicitly historical sciences is complex, multi-stranded and, within limits, indefinite. Attempting to shoe-horn explanation into a one-size-fitsall form represents nothing less than the dumbing-down of explanation.

Timothy Taylor is in the Department of Archaeological Sciences, University of Bradford, Bradford BD7 IDP, UK. 